\title{
Hospitalists in the ICU: Necessary But Not Sufficient
}

\author{
Scott A. Flanders, MD ${ }^{1,2 *}$, Colin R. Cooke, MD, MSc ${ }^{2,3}$
}

'Division of Hospital Medicine, Department of Internal Medicine, University of Michigan Medical School, Ann Arbor, Michigan; ${ }^{2}$ Institute for Health Policy and Innovation, University of Michigan, Ann Arbor, Michigan; ${ }^{3}$ Division of Pulmonary and Critical Care Medicine, Department of Internal Medicine, University of Michigan Medical School, Ann Arbor, Michigan.

$\mathrm{n}$ the United States, up to 6 million patients are admitted to intensive care units (ICUs) annually at a cost estimated to exceed $\$ 80$ billion or about $13 \%$ of total hospital costs. ${ }^{1,2}$ It also appears that as our population ages and illness severity increases, demand for ICU care is increasing. ${ }^{3}$ Given its importance, the organization and delivery of critical care has been extensively studied. High-intensity physician staffing by an intensivist (all patients managed or comanaged by an intensivist), while inconsistently shown to be associated with improved outcomes, has been endorsed as a high-quality care model by professional societies and the Leapfrog group. Despite its adoption by many hospitals, widespread implementation has been hampered by a national shortage of intensivists that continues to worsen over time. Hospitals, by necessity, look to alternative models to care for critically ill patients, and one such model is the use of hospitalists.

The Society of Hospital Medicine estimates that there are nearly 50,000 hospitalists practicing in the United States, and several studies show they routinely provide care in the nation's ICUs. ${ }^{4}$ While in some ICUs hospitalists work alongside intensivists, in many, they work without intensivist support, and regardless of the model, they often serve as the primary attending physician. There is good reason to think this model of care would be effective. Most hospitalists are internists, graduating from training programs that tend to emphasize care of acutely ill hospitalized patients. Hospitalists are often present in the hospital 24/7, are comfortable working in multidisciplinary teams, and routinely engage in quality improvement, which are all characteristics common in highly functioning ICUs. Yet, a study in this issue of the Journal of Hospital Medicine raises some concern.

Sweigart and colleagues ${ }^{5}$ surveyed 425 hospitalists to understand the structure and perception of their ICU practices. Consistent with prior studies, $77 \%$ provided ICU care with $66 \%$ serving as the primary attending. A novel finding is the high level of angst and lack of support hospitalists perceived in caring for these critically ill patients. Among rural hospitalists, $43 \%$ reported they were expected to practice beyond their perceived scope of practice, and almost a third reported they

\footnotetext{
*Address for correspondence and reprint requests: Scott A. Flanders, MD, 3119F Taubman Center, 1500 E. Medical Center Drive, Ann Arbor, MI 48109; Telephone: 734-232-6519 Fax 734-936-7024; E-mail: flanders@umich.edu
}

Received: August 16, 2017; Accepted: August 18, 2017

Published online first December 6, 2017

2018 Society of Hospital Medicine DOI 10.12788/jhm.2891 never had sufficient intensivist support. Even more concerning is that among hospitalists serving as the primary attending, over two-thirds reported difficulty transferring patients to a higher level of care (Sweigart et al.5). While we have concerns over how representative this sample is of hospitalist practice (the survey response rate was only about 10\%), it does appear that many hospitalists feel very uncomfortable with the ICU care they are providing and perceive barriers to moving their patients to a potentially safer care setting.

While one might argue more intensivists would solve this problem, calls for more intensivists are shortsighted, as there are compelling reasons to believe that such efforts will do little to address the mismatch between patient need and provider supply. Graduate medical education slots for intensivists cannot be easily and affordably increased, and even if more intensivists could be trained, there are few incentives to encourage them to work where they are needed most. Prioritization of intensivist training also diverts resources from training demands in equally important undersupplied specialties such as primary care. ${ }^{6}$ Finally, simply increasing intensivist supply fails to attend to important issues surrounding the multidisciplinary nature of care in an ICU, which relies heavily on multiple providers communicating and collaborating to provide optimal care. As noted in the study by Sweigart and colleagues, ${ }^{5}$ even in settings where intensivists were available 24 hours per day or made all major decisions, nearly one-third of hospitalists felt they practiced beyond their scope of expertise, suggesting that more intensivists may do little to improve hospitalists' comfort in caring for patients in the ICU.

In lieu of increasing intensivist numbers, policymakers should consider several strategies that have the potential to improve the quality of care delivered to patients in the ICU without increasing intensivists. Recent data suggest that some ICU patients can be safely managed by physician assistants and nurse practitioners. ${ }^{7.8}$ Care models involving such providers may free up overworked intensivists and hospitalists, allowing them to focus their efforts on the sickest patients. ICU telemedicine has also emerged as a promising tool that can bring the expertise of intensivists to hospitals where they are needed. Beyond the additional oversight of routine care practices it provides, telemedicine could allow rapid and real time consultation with intensivists for clinicians at the bedside facing difficult management decisions, potentially saving lives. ${ }^{9}$ The rapid growth of clinically integrated networks, which often include large wellstaffed medical centers surrounded by many smaller regional hospitals, might facilitate faster implementation of innovative 
telemedicine models. Regionalization of care is a third strategy that may improve the quality of care for the critically ill without increasing intensivist supply. Regionalization seeks to selectively transfer the most ill patients to high-volume centers with the greatest expertise in critical care, a practice associated with reduced mortality. ${ }^{10}$ Of course, for regionalization to be successful, front-line providers like hospitalists need to be able to orchestrate the transfer to the referral center, a process that, as noted by Sweigart and others, is neither easy nor universally successful. ${ }^{11}$

A final strategy would be to reduce the demand for intensivists through limiting the number of individuals in an ICU. While policies that explicitly ration ICU beds for individuals who have the greatest ability to benefit are ethically problematic, reductions in ICU beds would force providers to implicitly allocate beds more efficiently. There are a multitude of studies showing that our nation's ICUs are often filled with patients who derive little benefit from intensive care. ${ }^{12,13}$ Further research on ethically sound strategies to avoid ICU admission for patients unlikely to benefit is desperately needed. With fewer patients in an ICU, the busy intensivist could focus on the sickest patients and spend more time communicating with hospitalists about patients they are managing together.

Regardless of the care models that develop, hospitalists will increasingly be called upon to staff ICUs. Hospitalists are necessary, but as the study by Sweigart et al. ${ }^{5}$ suggests, just throwing them into our current ICU models with little support from their critical care colleagues is not sufficient. In the absence of a major influx of new intensivists, hospital medicine and critical care professional societies need to actively collaborate to develop creative training and educational models that provide hospitalists with the necessary skills to care for the critically ill and to lead the multidisciplinary care teams they will work within. More importantly, these professional societies must advocate together for more substantial reform to our current ICU care models. Novel solutions that prioritize the efficient use of existing ICU beds for those individuals with the greatest ability to benefit, but also capitalize on emerging technologies and regional centers of excellence, have great potential to address the mismatch between supply and demand. Given the increasing demand and substantial cost for ICU care, we can't afford to continue with business as usual.

Disclosure: The authors declared no conflicts of interest.

\section{References}

1. Pastores SM, Dakwar J, Halpern NA. Costs of critical care medicine. Crit Care Clin. 2012;28(1):1-10, v.

2. Nguyen $Y L$, Kahn JM, Angus DC. Reorganizing adult critical care delivery: the role of regionalization, telemedicine, and community outreach. Am J Respir Crit Care Med. 2010;181(11):1164-1169.

3. Halpern NA, Goldman DA, Tan KS, Pastores SM. Trends in Critical Care Beds and Use Among Population Groups and Medicare and Medicaid Beneficiaries in the United States: 2000-2010. Crit Care Med. 2016;44(8):1490-1499

4. Hyzy RC, Flanders SA, Pronovost PJ, et al. Characteristics of intensive care units in Michigan: Not an open and closed case. J Hosp Med. 2010;5(1):4-9

5. Sweigart JR, Aymond D, Burger A, et al. Characterizing Hospitalist Practice and Perceptions of Critical Care Delivery. J Hosp Med. 2018;13(1):6-12.

6. Kahn JM, Rubenfeld GD. The myth of the workforce crisis. Why the United States does not need more intensivist physicians. Am J Respir Crit Care Med. 2015;191(2):128-134.

7. Gershengorn HB, Johnson MP, Factor P. The use of nonphysician providers in adult intensive care units. Am J Respir Crit Care Med. 2012;185(6):600-605.

8. Gershengorn HB, Wunsch H, Wahab R, et al. Impact of nonphysician staffing on outcomes in a medical ICU. Chest. 2011;139(6):1347-1353.

9. Kahn JM, Le TQ, Barnato AE, et al. ICU Telemedicine and Critical Care Mortality: A National Effectiveness Study. Med Care. 2016;54(3):319-325.

10. Kahn JM, Linde-Zwirble WT, Wunsch $H$, et al. Potential value of regionalized intensive care for mechanically ventilated medical patients. Am J Respir Crit Care Med. 2008;177(3):285-291.

11. Bosk EA, Veinot T, Iwashyna TJ. Which patients and where: a qualitative study of patient transfers from community hospitals. Med Care. 2011;49(6):592-598.

12. Admon AJ, Wunsch H, Iwashyna TJ, Cooke CR. Hospital Contributions to Variability in the Use of ICUs Among Elderly Medicare Recipients. Crit Care Med. 2017;45(1):75-84.

13. Seymour CW, Iwashyna TJ, Ehlenbach WJ, Wunsch H, Cooke CR. Hospital-level variation in the use of intensive care. Health Serv Res. 2012;47(5):2060-2080. 